\title{
SOCIOLOGIA FEMINISTA DO HUMOR OU O RISO DE ZECA
}

\author{
Ivone Gebara*
}

Em recente conversa com meus botões enquanto passava roupa numa das muitas noites de minha quarentena comecei a pensar em como celebrar a vida da querida Zeca através de um texto. Queria alguma coisa que colocasse em relevo não apenas as suas qualidades pessoais, mas que sem renunciar a elas, aparecesse um traço de sua forma de fazer sociologia da religião. Muitas coisas me vieram à mente e era difícil escolher. Porém acabei guardando uma e tentei refletir sobre ela, pois sempre me chamava a atenção especialmente em seu método de trabalho. Trata-se de algo que certamente vocês concordarão comigo.

Enquanto passava e dobrava minha roupa, minha memória percorreu muitos caminhos desde os anos 1970 quando nos conhecemos. Éramos as duas jovens aventurando-nos em opções novas em comunidades inseridas em meio popular. Foram muitas as estradas percorridas... Muitas as dificuldades... Muitas as esperanças... Muitos os sonhos... E alguns deles voltaram à minha memória com uma nota de alegria e otimismo mesmo em meio às muitas dores e contradições da vida atual.

Entre as muitas lembranças, de repente me veio como uma imagem viva o cativante e iluminado riso da Zeca. Seu sorriso e seu bom humor me invadiram como inspiração. Encontrei neles o 'leit motiv' de meu texto. Seu humor agradável e contagiante começou a ser pensado por mim como uma 'mediação analítica' importante na linha de uma metodologia desafiadora em vista de uma epistemologia crítica da sociologia.

* Doutora em Filosofia pela Universidade Católica de São Paulo e em Ciências Religiosas pela Universidade Católica de Louvain. Foi professora de filosofia e teologia no Instituto de Teologia de Recife durante o bispado de Hélder Câmara. É integrante da Associação de Teólogos do Terceiro Mundo, assessora grupos e é convidada como docente por universidades no Brasil e no exterior. 
Provavelmente os leitores/as e as companheiras que homenageiam a querida Zeca nos seus 75 anos de vida vão se espantar com mais uma loucura da Ivone. Mas, de fato, acho que o humor é uma mediação analítica importante. É uma emoção e uma arte que poucos sabem usar e cultivar para analisar o mundo. E aprendi algo desse método pedagógico com Zeca, muito embora eu me sinta ainda dando os primeiros passos e pouco dotada para aprofundar sua riqueza.

Em 1980 o filósofo Roger Garaudy (1980) publicou um livro chamado 'Dançar a Vida' cujo foco era considerar a importância da dança na vida e nas suas diferentes expressões ao longo da história dessa arte tão importante. E eu, inspirada na Zeca, imaginei algo parecido como 'Rir a vida' como se a arte do riso pudesse ser recuperada como uma função cognitiva importante.

Roger Garaudy começa o primeiro capítulo de seu livro com uma pergunta muito interessante: "Que aconteceria se, em vez de construirmos nossa vida, tivéssemos a loucura ou a sabedoria de dançá-la?" (Roger GARAUDY, 1980, p. 13).

Parafraseando Garaudy, porém me referindo a um aspecto aprendido da metodologia de Zeca, ouso afirmar: Que aconteceria se, em vez de analisarmos nossa vida social apenas a partir dos métodos científicos, tivéssemos a loucura ou a sabedoria de tratá-la com humor? O que aconteceria se aprendêssemos a rir dela, rir de nós, rir entre nós? Ou o que aconteceria se o humor fosse parte de nosso método educativo?

Descobri essa metodologia e mediação observando e lembrando das exposições de Zeca sobretudo nas conferências ou seminários promovidos por 'Católicas para o direito a decidir' e aulas que ela ministrava. Tive algumas vezes o prazer de estar presente e de participar das reflexões propostas. Além disso, ouvi de muitas de suas alunas/os a delícia e a leveza de ter aula com ela pois a gente aprende a analisar as relações sociais com profundidade e humor. Imaginem introduzir o humor numa análise crítica da sociedade! Parece brincadeira! Introduzir humor não numa revista em quadrinhos ou num programa de TV ou num circo. Introduzir o humor na Academia, na faculdade de sociologia, nos estudos das ciências religiosas, nos congressos de teoria feminista, como diretora presidente de 'Católicas'. Que sadia ousadia! 
O humor é de fato um método analítico que pode criar desconfiança à primeira vista, porém a meu ver é digno de ser analisado e é extraordinariamente confiável sobretudo por seus efeitos positivos. Por isso vou tentar abrir aspectos desse humor metodológico que poderão talvez nos fazer rir criticamente e, alegremente louvar e agradecer a vida de nossa querida homenageada.

Minha memória e minha amizade por Zeca serão a fonte primeira desse texto.

\section{A FUNÇÃO REFLEXIVA DO HUMOR}

Muitas vezes percebi que Zeca começava uma reflexão com o contrário do que iria defender, mas o fazia de maneira tão séria que levava a provocar o riso do público. Um começo inesperado e um riso inesperado e contagiante. Um riso pensante. Um convite para pensar mais profundamente a vida rindo dela!

Instaurava-se assim através do humor o momento reflexivo. O público se dá conta de algo absurdo, de uma incoerência, provavelmente presente em muitas interpretações sociais, políticas e religiosas ou em seus próprios comportamentos habituais. O público ri com Zeca e o riso serve de corretivo à reflexão e um apelo a uma nova compreensão do problema analisado. O riso abre 'o estado da questão', permitindo as análises subsequentes, abrindo brechas, insinuando dúvidas, provocando a curiosidade analítica.

O humor introduz uma ruptura no curso habitual das ideias, daquilo que imaginamos ser uma aquisição teórica tranquila ou uma verdade absoluta. É como se ele quebrasse uma expectativa ou surpreendesse o público à espera de uma análise séria e formal. Abre-se para um jogo de linguagem, de imagens e novos significados através de uma frase, uma interrogação, uma careta, uma mímica, uma risada. O gesto distende e permite que o público avance na reflexão proposta tendo inclusive coragem de acrescentar novos aspectos à reflexão que o humor da mestra permite. Rir é uma capacidade de todos, mas rir como forma de reflexão é algo que se aprende apenas com algumas pessoas. Dessa forma fina e competente o humor produz efeitos pedagógicos e metodológicos impressionantes. 
O mais interessante é que Zeca não estudou o humor ou o riso como método. Não o decidiu a priori como método, não o aperfeiçoou como técnica e arte. Ela o expressa naturalmente e o integra em sua vida e de maneira especial na sua vida acadêmica de pesquisadora, educadora e professora. Então essa naturalidade de seu ser acopla-se a seu magistério e à sua metodologia de trabalho. Transforma-se em possibilidade para outras/os de manifestarem seus dons e produzir reflexões muitas vezes inesperadas e diferentes das repetições habituais. Abrir-se ao riso como identificando algo de especial que não havia sido percebido antes torna o novo conhecimento quase inesquecível. A circunstância do riso fixa o aprendizado. Esse procedimento faz até lembrar da maiêutica socrática, a arte de parturição das ideias, na qual os discípulos de Sócrates se treinavam a fazer sair de dentro de si mesmos argumentos para defender ou atacar um comportamento ou uma situação. A maiêutica de Zeca é em grande parte o riso, o humor, a leveza no pensamento para enfrentar-se às muitas contradições e dificuldades que a sociedade encerra ou que certas teorias impuseram como 'a verdade'.

Rir é agradável. Alivia tensões, congrega, aproxima, entusiasma, contagia positivamente. Quem já assistiu a uma conferência da Zeca deve ter provado as delicias de seu método espontâneo e por isso mesmo eficaz para fazer rir e para fazer pensar. É nesse sentido que se pode dizer que o humor tem a ver com a verdade, ele desnuda o rei, desnuda os poderes, desnuda nossas pretensões, abre os muitos sentidos escondidos nas afirmações gerais e dogmáticas. O humor nos incita a refletir de maneira mais ampla e profunda e quando saímos dele podemos nos enfrentar com mais qualidade e empenho a buscar novas razões, novos sentidos e novas ações.

Há uma lógica no humor que ao parecer escapar da racionalidade habitual instaura uma outra racionalidade porque permite o nascimento da dúvida e de novas construções de sentido. Por exemplo afirmar diante de um público que 'Deus ama igualmente todos os homens', afirmação repetida nos púlpitos à exaustão pode levar a um jogo de palavras e expressões faciais que criam dúvidas em relação a esse tipo de afirmação. Ao dizer com ênfase apenas: 'de fato ama' ... porque eles estão nos 
mais altos postos políticos e religiosos... Introduz-se a dúvida, o riso e a possibilidade de pensar no sentido dessa afirmação. Ou ainda, afirmar: 'As igrejas cristãs promovem a liberdade de escolha das mulheres'... Em seguida se enfatiza sorrindo: 'sim de fato, elas podem escolher a marca de sabão em pó para lavar as roupas de casa e do clero'. Cria-se um impacto cognitivo e reativo provocador de riso e a possibilidade de um pensamento diferente.

A contração muscular facial expressão visível da força inesperada do riso que invade todo o corpo revela um assentir de uma compreensão da crítica feita e da nova proposta que emerge de forma lenta e segura. A racionalidade aparentemente escondida em meio ao riso inesperado é imediatamente resgatada como reflexão. O caminho do riso é quase direto, eficaz e não comporta grandes explicações e malabarismos mentais.

Rimos! Rimos e pensamos o já pensado discordando e propondo novas possibilidades de compreensão e de análise. Avançamos no conhecimento abrindo-o a novas possibilidades e interpretações que se adequam mais as questões de nosso tempo e espaço. Desestruturam-se certezas passadas, sai-se da rotina conhecida como se fôssemos alcançar um patamar mais próximo do horizonte desejado.

Magistralmente Zeca conduz seu público a refletir criticamente, a descobrir os argumentos obscuros e insustentáveis nas pretensas afirmações absolutas que caracterizam os pensamentos pré-preparados e cozidos em 'verdades' aparentemente irrefutáveis e absolutas. Seu humor convida ao pensamento! Seu pensamento convida a dar passos como se preparássemos um novo roteiro de compreensão de nosso mundo e de nós mesmas. Instaura-se a dialética do riso, do humor em vista do conhecimento dos múltiplos aspectos da realidade social.

\section{O HUMOR COMO CRÍTICA SOCIAL}

No século XIX o filósofo francês Henri Bergson (2007) escreveu um livro sobre a importância do riso. O riso como expressão de uma ruptura cognitiva que surpreende e modifica a percepção da realidade. Irrompe quase como um jogo na linguagem corrente, no desenvolvimento de ideias como se um intruso se misturasse à seriedade da solenidade de 
uma aula ou de uma conferência. O humor, o humor bom, introduz uma nova destinação ao pensamento como se através dele o senso crítico muitas vezes adormecido fosse despertado. E rimos, do que é contado, e rimos do sorriso malicioso desenhado no rosto de quem nos fala. $E$ ao rir nos damos conta do risível de certas situações, de certas análises, de certas crenças e até de certas teorias que defendemos por muito tempo. Ao rir relativizamos a seriedade dos argumentos de autoridade, dos costumes habituais, das solenidades pré-estabelecidas, das formalidades que povoam o mundo acadêmico, dos cenários perfeitos que imaginamos. Nos surpreendemos com a ingenuidade de nossas crenças, de nossas afirmações usuais irrefletidas. O riso inesperado é como um pequeno acidente de percurso que nos faz despertar e prestar mais atenção ao que ouvimos, pensamos e falamos.

Ao rir parece que oxigenamos nosso corpo com uma energia agradável que nos permite estar mais atentas ao que segue e mais preparadas para desarmar nossas pretensas certezas e a de outros e a acolher novidades em nosso entorno. Assim o humor introduzido na seriedade acadêmica pode ajudar a apreender realidades sociais ou mesmo pessoais, ou análises talvez difíceis de serem feitas e aceitas de outra maneira.

O humor pode ser mais simpático ao público que a aridez de uma argumentação sociológica ou filosófica em que a primazia da racionalidade fria vigora como método de pensamento. A complexidade do exposto cansa e facilmente o pensamento desliga e vagueia para outras situações e pensamentos. Porém, com humor o pensamento se fixa melhor e, o resultado da compreensão do que se quer expor parece ser maior.

Os estudiosos do riso sempre o consideraram uma forma de corretivo, um lembrete jocoso para afirmar a necessidade de uma ordem social que favoreça o bem comum.

O humor tem dessa forma positiva uma função crítica. Basta lembrar o papel do 'bobo da corte' que não só tinha que fazer o rei e a corte rirem, mas chamava com frequência a atenção dos presentes para as políticas anti populares apoiadas pelo rei e seus ministros. A corte ria muitas vezes sem perceber que riam de suas próprias ações. Por isso se diz que os bobos da corte não eram nada bobos. Possuíam várias 
habilidades: versejavam, faziam malabarismos e mímicas além de terem sensibilidade social e sabedoria política marcantes. O bobo é também aquele que lembra ao rei que ele é apenas um mortal, que partilha da condição humana em todos os seus aspectos. Tudo isso para evitar que mergulhe na embriaguez do poder solitário e autocrático e distanciar-se das necessidades do povo.

O humor ou o riso aponta o dedo para nossas rugas, cabelos brancos, falhas, limites, deformações e contradições que queremos esconder. Escancara a verdade nua e crua e a torna aceitável no riso. Torna-se com isso um grande instrumento de consciência pessoal e coletiva e de possível mudança social.

É essa extraordinária metodologia de análise social que descubro no magistério de Zeca, metodologia crítica e bem humorada que convida ao pensamento e à ação em vista de uma reorganização da vida.

\section{O HUMOR COMO CRÍTICA DA RELIGIÃO}

Imaginem o riso de uma socióloga feminista da religião frente a velhas elaborações teológicas e simbologias erigidas como verdades a serem cridas em tempos de nova antropologia filosófica, de ciência, tecnologias de ponta e movimentos sociais plurais! Imaginem a vigência de proibições às mulheres de representação ou de decisão sobre suas vidas a partir de uma imagem masculina de Deus!

O humor metodológico não se refere primeiro aos que creem, mas aos que mantêm uma crença popular mágica metafísica que aliena o povo de sua realidade, crença que talvez eles mesmos não creiam mais. Porém as mantêm por conveniência, por opção política, por tradição estática e infelizmente para usufruir lucros no grande mercado da religião.

É sobretudo em relação à autonomia das mulheres e a uma nova prática em relação aos seus corpos que se estrutura a crítica de Zeca à religião e de maneira especial à instituição católica à qual ela se dirige prioritariamente.

A questão que nos ocupa e a ocupa especialmente, tem a ver com o mal-estar de perceber o quanto as religiões e nelas a vida social são regidos por sistemas míticos metafísicos formulados num passado distante. Ou ainda por visões em que o individuo é o centro do mundo 
e julgado pessoalmente por Deus e pelos homens. Julgamento específico, sobretudo direcionado às mulheres consideradas mais culpadas em relação ao sexo do que os homens. Por isso certos pecados como a interrupção da gravidez ou o uso de anticoncepcionais ou o respeito à diversidade sexual encontram resistência por parte dos líderes religiosos irmanados aos líderes políticos.

Significações imutáveis propostas pelas crenças religiosas já não sustentam o pluralismo do mundo humano atual. Onde residiria a verdade imutável, a preexistente, aquela que se afirma como conduta querida por Deus? Afinal de que Deus se está falando?

Para proteger-nos da morte criamos as religiões e as tornamos escudos de amparo e proteção. Mas estes se tornaram hoje inadequados, como se fossem roupas de papel molhadas por intensa chuva. Não nos protegem mais. Não nos abrigam e nem abrigam nossos sonhos. Hoje, construímos outras significações que também passarão amanhã. Por isso precisamos acreditar mais na capacidade de criar sentidos plurais, de trocá-los quando necessário e não os impor como absolutos para nós e para os outros.

Rir de nossas imagens, de nossos absurdos e absolutos para flexibilizar os pensamentos religiosos e convidá-los a tocar o mais importante para o hoje.

Ao escrever sobre a importância do riso não podemos esquecer do célebre romance de Umberto Eco, 'O nome da rosa', onde a questão do riso é levada a sério em torno de um livro de Aristóteles (1932) no qual ele afirma ‘o riso como próprio do homem' e que o riso serviria para destruir a seriedade de nossos adversários. Essa questão se tornou polêmica especialmente na Idade Média. Por isso, no romance de Humberto Eco este livro se torna central e foi queimado pelo bibliotecário depois de ter sido objeto de intrigas e assassinatos. A razão pela qual o frade bibliotecário comete esse crime é que para ele o riso era uma espécie de desobediência a Deus. Segundo alguns pensadores medievais 'Deus não ri' e nem Jesus nos Evangelhos parece ter rido. Deus é severo, justo juiz, um sério ancião pronto para o julgamento de nossas ações. Mas, os modernos modificaram essas concepções e aprenderam a valorizar a importância do riso. E, nós contemporâneas/os também 
o valorizamos embora também reconheçamos o quanto certos risos, os bullyings atuais, podem ser também destruidores quando dirigido a pessoas ou grupos marginais que se gostaria de eliminar.

A função crítica social, metodológica e educativa do humor tem se manifestado útil nas muitas disciplinas do saber humano. E, é isso que descubro no trabalho de Zeca sempre sublinhando a importância da dimensão ética em relação às crenças metafísicas que não nos sustentam mais. Seu humor nos deixa perceber as muitas alienações às quais nos sujeitamos na adesão a crenças religiosas e políticas e a urgente necessidade de refazer o tecido de nossas convicções desfazendo os muitos equívocos e pondo luz nas trevas que ainda atormentam as nossas consciências.

\section{O HUMOR COMO RESGATE DA ALEGRIA DE VIVER}

O animal humano adquiriu a capacidade de rir há milhares de anos de evolução. Rir é algo próprio desse animal que somos embora alguns chimpanzés também tenham chegado a essa evolução. Homens e mulheres riram em muitos momentos de suas vidas e seu riso teve várias significações, razões ou sem razões. A etimologia latina da palavra rir, 'ridere', sugere uma contração dos músculos faciais por algo que produz alegria ou um contentamento pontual. Uma contração que vem de dentro e de fora e explode em ruído contagioso. A palavra riso faz lembrar 'les rides' em francês, 'as rugas' em português como se nos enrugássemos contraindo-nos diante de algo agradável, algo que gostamos, algo que estimulou positivamente como um aperitivo ou um antepasto para em seguida comer algo mais substancial e mais refletido criticamente. Mas, não se pode esquecer também dos risos de contração nervosa, risos de medo, de excessos de controle dos quais se quer fugir. Então se ri e se chora ou se chora rindo. Não analiso aqui essas formas, mas apenas aquelas que têm a ver com novas possibilidades para fazer avançar o conhecimento humano. Nessas, a contração muscular antecede uma descontração instantânea, uma expansão do corpo e da possibilidade de pensar de forma diferente. Ela se inicia com o riso, a gargalhada, o contágio da nova energia que circula. É nessa perspectiva que afirmo que no interior mesmo 
da sociologia analítica do riso há um resgate da alegria de viver, um resgate de possibilidades de mudança para melhor.

Resgatar a alegria de viver pode parecer à primeira vista um tema distante da seriedade das análises científicas. Porém uma pergunta precisa ser feita: Para que servem as análises científicas? Qual é o objetivo último que perseguem?

Se a ciência na sua diversidade serve para ajudar os seres humanos a viver melhor, a enfrentar doenças e múltiplas dificuldades ou sofrimentos poderíamos dizer que a razão última das ciências está na felicidade humana. Este termo infelizmente muito açucarado e banalizado pelo capitalismo de Mercado deve ser recuperado como indicador da finalidade humana no imediato da vida, no imediato das instituições sociais e no mediato e imediato das ciências. Se se fala de felicidade há que se falar do humor. Humor como condimento de nossas buscas, humor frente ao desmoronamento de valores e expectativas, humor como capacidade de rir esperançosamente diante da necessidade de superar o caos social no qual nos encontramos.

Rir ou provocar o riso é uma forma de terapia individual e coletiva que produz novas busca e novas possibilidades de ação. Lembro-me de ter assistido a uma conferência na Colômbia de uma psicóloga que trabalhava com mulheres pobres estupradas. Depois de ouvir em meio a muitas lágrimas os lamentos e a descrição das várias formas de agressão que haviam sofrido a psicóloga lhes propunha narrar a fealdade presente no corpo dos agressores. Uma falava de seu mau cheiro e o assemelhava a um porco sujo e todas riam. Outra falava de seu pênis descomunal parecendo uma trompa de elefantes e todas riam. Outra falava da vontade de ter uma faca para decepar os testículos ou os 'ovos' do agressor para conservar a linguagem das mulheres. E todas riam. Não ficavam apenas na tragédia do acontecido. Inventavam outras estórias como formas depurativas de seus males. E riam com gosto apesar do fundo amargo. Nestes risos havia uma outra energia que lhes ajudava a levantar a cabeça e, ao rirem juntas, se aproximarem umas das outras através de algo diferente que agora lhes estava dando alguma esperança de cura dos traumas vividos.

Na mesma linha se pode falar de outros aspectos da vida que merecem ser visitados pelo riso e sua riqueza pedagógica. Paradoxalmente 
a ciência analítica necessita do humor como para dizer que ao rirmos de nossas próprias produções estamos a caminho da criação de outras coisas ao longo de todos os tempos, espaços e criações humanas quer na ciência quer na arte ou nas crenças religiosas.

O riso produz uma flexibilidade maior de nosso corpo e sem dúvida uma criatividade de nosso pensamento. Relaxa a censura, nos tira de nossa rigidez e por isso a tradição popular não hesita em reafirmar que 'rir é o melhor remédio'.

\section{BREVÍSSIMA CONCLUSÃO}

Zeca querida, para terminar essas linhas que dedico a você com muito carinho quero ainda contar um segredo. Descobri em meu atrevimento que por trás de seu riso, de seu sorriso, de seu humor competente você sempre se mostrou ser a advogada das enjeitadas, das recusadas pelo afeto, das sem direitos e sem leis, das acusadas injustamente de delitos, das abandonadas à própria sorte por terem decidido os rumos de sua vida. Descobri que por trás de seu riso você carrega as lágrimas de muitas que famintas de pão e de amor se sentem abandonadas e excluídas das missas solenes, castigadas por Deus, recusadas por seus santos ministros. Descobri que seu riso tem os sussurros das ações a contra corrente, que há nele novas notas em claves e rabiscos singelos, novas canções e novos caminhos para tantas mulheres abandonadas ou injustiçadas. Seu riso não é só um método, não é só uma estética natural de seu ser. Há nele a ira daquelas que não podem consentir que o pão de cada dia seja apenas de alguns e algumas. O pão deve ser nosso e bom. E não só o pão, mas também o vinho da uva e da festa, do bem viver e do bem querer.

Por trás de seu humor esconde-se um amor que quebra as regras rígidas da ordem religiosa e política, esconde-se uma ética da transcendência da vida real para além de qualquer ordem. Por trás de seu humor esconde-se a negação de um ídolo divino subalterno aos grandes desse mundo. Por trás de seu riso gostoso delineia-se a mulher iconoclasta das regras rígidas, das santidades impostas como caminho para um céu de purezas imaginárias. Seu riso, sorriso, risada denuncia a anacrônica hipocrisia dos guardiões da ordem perfeita, do dever imposto para os 
outros e das regras que levam à morte. Seu sorriso, sua palavra e seu olhar direto denunciam aqueles que se julgam no direito de interferir na vida das mulheres julgando-se bons conselheiros ou libertários inspirados. Você acorda as sonâmbulas, dá a mão às aflitas, empresta sua voz às que apenas soluçam. E ri... E seu riso faz pensar e ensina o que os doutos escondem das mulheres.

Obrigada por rir e nos ajudar a dar passos em meio às tormentas e aflições de nosso tempo. Obrigada por entregar pequenas esperanças através de um dedo de prosa agradável e nos oferecer um pão de queijo quentinho e delicioso vindo das terras das Minas Gerais onde 'correm o leite e o mel' em abundância e ternura.

$* * *$

Zeca que bom que nos encontramos nessa história comum, em 'nossa casa comum', nesse tempo comum. Que bom que você existe, que nos ajuda a colher as pequenas flores do campo que nascem 'do impossível chão' e especialmente nos provoca a rir misturando o riso ao pão de cada dia.

Obrigada por ser essa intelectual artista do humor/amor e nos ajudar a reinventar nosso mundo e nossa liberdade com mais alegria.

Feliz aniversário!

Com muito carinho, gratidão e reconhecimento...

Sua velha amiga,

\section{Ivone Gebara}

São Paulo, junho 2020.

\section{REFERÊNCIAS}

ARISTOTELES. Poétique, VI. Les belles lettres,1932.

BERGSON, Henri. O riso - ensaio sobre a significação da comicidade. São Paulo: Martins Fontes, 2007.

GARAUDY, Roger. Dançar a Vida. São Paulo: Editora Nova Fronteira, 1980. 